\title{
The Impact of Multiple Concussions on Emotional Distress, Post-Concussive Symptoms, and Neurocognitive Functioning in Active Duty United States Marines Independent of Combat Exposure or Emotional Distress
}

\author{
James L. Spira, Corinna E. Lathan, ${ }^{2}$ Joseph Bleiberg, ${ }^{3}$ and Jack W. Tsao ${ }^{4}$
}

\begin{abstract}
Controversy exists as to whether the lingering effects of concussion on emotional, physical, and cognitive symptoms is because of the effects of brain trauma or purely to emotional factors such as post-traumatic stress disorder or depression. This study examines the independent effects of concussion on persistent symptoms. The Defense Automated Neurobehavioral Assessment, a clinical decision support tool, was used to assess neurobehavioral functioning in 646 United States Marines, all of whom were fit for duty. Marines were assessed for concussion history, post-concussive symptoms, emotional distress, neurocognitive functioning, and deployment history. Results showed that a recent concussion or ever having experienced a concussion was associated with an increase in emotional distress, but not with persistent postconcussive symptoms (PPCS) or neurocognitive functioning. Having had multiple lifetime concussions, however, was associated with greater emotional distress, PPCS, and reduced neurocognitive functioning that needs attention and rapid discrimination, but not for memory-based tasks. These results are independent of deployment history, combat exposure, and symptoms of post-traumatic stress disorder and depression. Results supported earlier findings that a previous concussion is not generally associated with post-concussive symptoms independent of covariates. In contrast with other studies that failed to find a unique contribution for concussion to PPCS, however, evidence of recent and multiple concussion was seen across a range of emotional distress, post-concussive symptoms, and neurocognitive functioning in this study population. Results are discussed in terms of implications for assessing concussion on return from combat.
\end{abstract}

Key words: adult brain injury; behavioral assessments; cognitive function; head trauma; military injury

\section{Introduction}

A PPROXIMATELY 1.5 Million AMERICANS survive a traumatic brain injury (TBI) from traffic accidents, assaults, sports, and work injuries, with the vast majority of these being primarily mild (mTBI), otherwise known as concussion. ${ }^{1}$ Concussion, however, is uniquely problematic in the military given the new strategies of war encountered by service members when fighting an insurgency using improvised explosive devices. The rate of concussion experienced by United States (U.S.) service members engaging in combat during the wars in Afghanistan and Iraq has been estimated at between $15 \%$ and $22 \% .^{2-4}$

Concussion can affect cognitive, somatic, and emotional functioning, including slowed and less accurate information processing, sensory sensitivity, imbalance, headaches, and emotional lability. ${ }^{5}$
Although most symptoms of concussion appear to dissipate within hours or days, lingering effects of concussion have been widely reported, ${ }^{6-8}$ with persistent post-concussive symptoms (PPCS) reported in between $15 \%$ and $50 \%$ of persons with mTBI, depending on how it is defined and assessed. ${ }^{5}$ Several studies show that at least a subgroup of persons do continue to have both subjective symptoms, ${ }^{9-13}$ physical symptoms, ${ }^{14}$ and lower cognitive test performance, even after 90 days. ${ }^{15,16}$

It has been argued, however, that the rates of PPCS are actually much lower or that any lingering symptoms are not from concussion at all, with any persistent effects on cognitive and somatic functioning exclusively because of the presence of concomitant emotional problems such as post-traumatic stress disorder (PTSD) and depression. ${ }^{2,17-21}$ Indeed, the extent to which the effects of concussion persist has been a topic of intense debate with substantial

\footnotetext{
${ }^{1}$ National Center for PTSD, US Department of Veterans Affairs, Pacific Island Division, Honolulu, Hawaii, and Department of Psychiatry, John A. Burns School of Medicine, University of Hawaii, Honolulu, Hawaii.

${ }^{2}$ AnthroTronix, Inc, Silver Spring, Maryland.

${ }^{3}$ National Intrepid Center of Excellence in Psychological Health and Traumatic Brain Injury (NICoE), Walter Reed National Military Medical Center, Bethesda, Maryland.

${ }^{4}$ Traumatic Brain Injury Program, Wounded, Ill, and Injured Directorate, U.S. Navy Bureau of Medicine and Surgery Falls Church, Virginia.
} 
clinical and policy implications, including recommendations that the military halt post-deployment assessment of post-concussive difficulties, focusing instead on emotional difficulties associated with cognitive and somatic complaints. ${ }^{22}$

The discrepancies between reports of PPCS in the literature may arise from several factors. First, the populations investigated may vary. Rates and symptom manifestations of PPCS across studies may be because of differential levels of emotional comorbidity in patients who were concussed from sports injury compared with accident, assault, or combat. Findings may also vary based on whether the sample studied was assessed in a clinical setting, leading to the possibility of exaggeration of self-reported symptoms because of secondary gain, compared with an anonymous sample outside a clinic setting.

Second, the influence of number and recency of concussions may not have been adequately assessed. Most studies compare the presence of a previous or recent concussion versus no concussion. The number of lifetime concussions, however, has not been adequately evaluated. A few recent studies have begun to show an association of multiple concussions with persistent neurocognitive and emotional symptoms. This is seen in long-term follow-up studies of professional contact sports ${ }^{23-25}$ as well as among active duty personnel. ${ }^{26}$ For instance, Bryan and Clemens ${ }^{27}$ recently found an association between lifetime number of concussions and suicidal ideation in a small sample of recently concussed military personnel, independent of the effects of depression and PTSD, yet whether these symptoms persisted weeks after the injury was not assessed.

Thirdly, the degree of co-occurring emotional, somatic, and cognitive disorders may cloud the assessment of the individual contributions of these factors to overall functioning, requiring sufficient assessment of these components along with analytic methods to tease apart their individual effects. ${ }^{28}$ Because there is a large overlap in post-concussive symptoms with symptoms common in patents with depression and PTSD, ${ }^{29-31}$ it is difficult to distinguish among these unless assessments of both concussion and emotional distress are administered together. It is additionally complex to assess the unique contribution of concussion to functioning in combat veterans because of the stress of combat during which service members are dealing with the ever present threat of death, being away from loved ones, and the stress of deployment. Indeed, Cooper and associates ${ }^{17}$ found that deployment stress was associated with PPCS, and Vesterling and colleagues ${ }^{32}$ found cognitive functioning declining across the deployment cycle, independent of concussion.

It is because of such an association between emotional distress commonly seen in combat and post-concussive complaints that many argue that post-concussive complaints are the direct result of emotional distress alone. It has also been argued, however, that concussion lowers the threshold for developing emotional problems. ${ }^{33}$ Morrisette and coworkers ${ }^{34}$ found evidence suggesting that recently deployed service members' concussions led to higher rates of depression and PTSD after deployment; Maguen and colleagues ${ }^{35}$ found an association between multiple concussions and rates of PTSD 2 years later in combat veterans; and Bryan ${ }^{26}$ found an association between number of concussions and sleep difficulty in deployed service members. Despite the many comorbid conditions that exist in military members who have been concussed, distinguishing the unique contributions of concussion from the effects of emotional distress is not always considered when studying the causes of PPCS.

Finally, few studies examining PPCS have assessed both objective measures of functioning, such as cognitive performance, along with subjective self-report of emotional and somatic functioning. It is well known that cognitive functioning can be impaired for at least the first few days after concussion. ${ }^{5,36}$ Speed and accuracy (and their combined measure of mental efficiency, throughput [TP]) have been shown to decline across a range of cognitive functions, including simple reaction time ${ }^{37}$ as well as delayed memory and executive functioning. ${ }^{15}$ Although this problem has been discussed for decades, few studies have examined the long-term effects of concussion on post-concussive neurocognitive functioning and corresponding subjective reports of cognitive, sensory, somatic, and emotional symptoms. ${ }^{38}$ The interpretation of cognitive dysfunction after concussion is complicated, because it is also known that emotional distress affects cognitive functioning. This may be even more complicated in combat veterans, because several studies have also shown that cognitive performance is affected by the stress of having been combat deployed. ${ }^{32,39,40}$

In light of the above discussion, there is little consensus as to the nature of persistent post-concussive symptoms in those with a previous concussion. Therefore, the aim of this study was to determine whether the recency and number of lifetime concussions had a sustained impact on emotional, somatic, and cognitive functioning in a sample of U.S. Marines, independent of deployment stress, and symptoms of depression and PTSD. A cohort of U.S. Marines was thought to be ideal for this examination because of the uniformity of the sample, the high rates of exposure to blast, the high rates of co-occurring PTSD and depression, and the high level of functioning compared with a patient population, allowing for an examination of the effects of concussion recency and number on cognitive and somatic functioning, relatively independent of self-report emotional difficulties or exaggeration of symptom because of secondary gain compared with a clinic sample. In addition, Marines from the same unit who had not been deployed or who had been previously (but not recently) deployed allowed for an analysis of the independent effects of deployment stress. Determining the separable effects of these factors will aid in the debate over whether assessment and treatment of concussion should continue in the military.

\section{Methods \\ Participants}

U.S. Marines $(n=646)$ from the Second Expeditionary Force (2MEF) participated in the single testing session reported here. Volunteer participants were all active duty service members in good standing (not on limited duty medical status or pending medical or disciplinary discharge). Testing took place in 2012 at Marine Base Camp Lejeune, where an entire neurobehavioral battery was administered, and at Marine Corp Air Grand Combat Center, Twentynine Palms, where the entire neurobehavioral battery was administered to some participants, but because of time constraints, only a portion of the neurobehavioral battery was administered to others (see list of measures). Marines were recruited for participation independent of their medical or deployment history.

\section{Procedure}

Medical officers arranged for 2 hours of time off from duties for service members who might be interested in participating in this study, informing them that researchers were developing an instrument that might eventually be used to improve medical problems in the field. Service members showed up at an appointed time in a classroom to hear a briefing about the research. After an explanation of the procedure that took place without the presence of 
commanding officers or senior enlisted personnel in their chain of command, volunteers were allowed to leave or sign the Department of Defense Institutional Review Board approved consent to participate. No remuneration was offered, and care was taken to insure that participation was voluntary, without recrimination for refusing to participate or leaving during testing. No identifiable information was collected, other than age, rank, and sex. There was greater than a $99 \%$ agreement to participate from those who came to hear the briefing.

Groups of approximately 20-40 consented service members were administered neurocognitive and self-report and psychological measures on a handheld computing device, in classrooms at either Marine Base Camp Lejeune or Marine Desert Warfare Training Center, Twentynine Palms. The full (Standard) testing battery reported here took approximately $40 \mathrm{~min}$ to complete, with the subset (Rapid or Brief) battery taking approximately $10 \mathrm{~min}$ (see list of measures). After an explanation of the procedure, handheld devices were distributed. For the neurocognitive tests, participants were instructed to answer as rapidly and accurately as possible. All tests were self-explanatory, beginning with written instructions. After completion of the test battery, service members were administered additional testing for determining reliability. Only the first test administrations are discussed here, because reliability of this instrument has been reported elsewhere. ${ }^{41}$

\section{Materials}

Testing materials was administered on a handheld computing device, programmed with the Defense Automated Neurobehavioral Assessment software (DANA). DANA combines a traditional Neuro Cognitive Assessment Tool (NCAT) with other behavioral assessments. All subjects were administered the DANA Standard battery consisting of eight different neurocognitive tests assessing speed and accuracy across a range of simple motor and visual discrimination to more complex memory and decision-making tasks, as well as five self-report psychological assessments. Subjects used a Trimble NOMAD handheld computing device and were instructed to use a stylus for consistency. The NOMAD uses the Android Operating System and has a 3.5-inch color pressure sensitive touch screen. This format is optimally suited for tests of speed and accuracy because it has less variability than can be achieved across various desktop computers.

DANA was funded by and developed for the Department of Defense for use by medical support personnel in the field to detect impaired performance because of deployment-related factors including concussion, emotional distress, or exhaustion. Although DANA uses standard assessments tools that have been well researched and widely utilized, because of its unique delivery system, DANA was tested under extreme field conditions as well as classroom settings, and found to have adequate test-retest $(>0.70)$ and split-half $(>0.80)$ reliability $^{41}$ and cross-platform validity compared with the Automated Neuropsychological Assessment Metric (ANAM), the standard neurocognitive assessment used by the military. ${ }^{42}$ Neurocognitive tests in the DANA Standard Battery used to assess speed and accuracy included Simple Reaction Time (SRT1), Procedural Reaction Time (PRT), Go-No-Go (GNG), Spatial Rotation Discrimination (SPD), Code Substitution Simultaneous (CDS), Code Substitution Recall (CDR), Sternberg Memory Test (STN), and a second Simple Reaction Time (SRT2).

Depending on the test, between 20 and 40 trials per test are administered, and average speed, accuracy, and TP are calculated for each of these tests. The Standard Battery also included five selfreport psychological tests: Post-Traumatic Symptom Disorder Check List, military version (PCL-M), Primary Care Health
Questionnaire depression module, minus the suicide question (PHQ-8); Pittsburgh Sleep Quality Inventory (PSQI), the Deployment Stress Inventory (DSI), a modification of the Neurobehavioral Symptom Inventory adapted for deployed service members that includes questions about anger and distress, and the Combat Exposure Survey (CES). For each behavioral assessment, total score was calculated. Accepted clinical threshold scores were calculated for dichotomous analyses. Demographic and concussion history was also included in the battery.

Neurocognitive measures. Data Cleaning was conducted for neurocognitive tests. Responses that are considered too fast (faster than $150 \mathrm{msec}$ for SRT and 250 for other measures) and lapses (slower than $850 \mathrm{msec}$ for SRT or timed-out for the response time for other tests, approximately $2000 \mathrm{msec}$ ) are considered incorrect responses and not calculated in mean, Standard deviation (SD), percent correct, or TP scores. Neurocognitive tests that have less than $66 \%$ correct responses are considered invalid. Valid summary test scores were calculated to determine mean correct (Mean), SD, percent correct (\% correct), and TP (mean correct responses divided by total trials within $1 \mathrm{~min}$ ), a test of cognitive efficiency. Descriptions of all assessment measures are listed below.

$S R T^{a, b, c}$. The subject taps on the location of the yellow asterisk symbol as quickly as possible each time it appears. This task measures pure reaction time.

$P R T^{a, b, c}$. The screen displays one of four numbers for $3 \mathrm{sec}$. The subject presses on a left button ("2" or " 3 ") or right button (" 3 " or " 4 ") depending on the number pressed. A choice reaction time measure of accuracy, reaction time, and impulsivity. This choice reaction time task targets simple executive functioning with easy decision-making capabilities.

GNG. ${ }^{a, b, c}$. This is a forced choice reaction-time task relevant to warfighters. A house is presented on the screen with several windows. Either a "friend" (green) or "foe" (white) appears in a window. The respondent must push a "fire" button only when a "foe" appears. A choice reaction time measure of sustained attention and impulsivity. The test assesses speed and accuracy of targets, omissions, and commissions.

$S P D^{b, c}$. Pairs of four-bar histograms are displayed on the screen simultaneously, and the subject is requested to determine whether they are identical. One histogram is always rotated either \pm 90 degrees with respect to the other histogram. Assesses visuospatial analytic ability.

$C D S{ }^{C}$. Subjects refer to a code set of nine symbol-digit pairs that are shown across the upper portion of the screen. A sequence of single symbol-digit pairs is shown below the key, and the subject indicates whether or not the single pair matches the code by pressing Yes or No. Assesses visual scanning and attention, learning, and immediate recall.

Code Substitution-Delayed Memory ${ }^{b, c}$ (CDD). After a delay of several intervening tests, the same symbol-digit pairs are presented without the code. The subject indicates whether or not the pairing was included in the code that was presented in the earlier Code Substitution learning section. Assesses learning and shortterm memory.

${ }^{a}$ DANA Rapid Battery.

${ }^{\mathrm{b}}$ DANA Brief Battery.

${ }^{\mathrm{c} D A N A}$ Standard Battery. 
STN. ${ }^{C}$. The subject memorizes a set of five letters, after which letters appear on the screen one at a time, and the subject determines if the letter on the screen is a member of the memory set. Assesses working memory.

Self-report measures. Self-report psychological questionnaires were programmed in DANA and administered on the handheld device after the neurocognitive assessments. One question appeared at a time. Wording was unchanged from the original questionnaires Service members were instructed to answer as accurately as possible, but that they could skip a question if it disturbed them.

PCL-M. ${ }^{C}$. A 17 -item scale assessing symptoms in response to stressful military experiences. This scale assesses PTSD, with subscales including Re-Experiencing, Avoidance/Numbing, and Hyperarousal. Higher scores indicate increased PTSD symptomatology. In a military population, scores $>50$ are in persons likely to have PTSD. For greatest specifically, scores $>44$ with three ReExperiencing, one Avoidance/Numbing, and two Hyperarousal endorsed as at least "most of the time" are more specific for PTSD and correlate very highly (0.92) with the Clinician Administered PTSD Scale (CAPS). ${ }^{43}$

Primary Care PTSD Screen ${ }^{b}$ (PC-PTSD). Four screening questions designed for use in clinical settings to screen for PTSD, with three of four endorsed items suggestive of likely PTSD. Questions assess Hyperarousal, Re-Experiencing, and Avoidance for PTSD Screening. This test is more sensitive than specific, but correlates highly with the PCL. ${ }^{44,45}$

PHQ8. An eight-item Depression Scale assessing symptom severity and diagnostic criteria for major depressive disorder. For research purposes, item \#9 (concerning suicide) was not included, yet previously published results indicate that the scoring, reliability, and clinical validity are similar. ${ }^{46}$ A person with a score of $0-9$ is likely to have no depression, 10-14 mild depression, 15-19 moderate depression, and $20+$ severe depression.

CES. ${ }^{c}$. A seven-item self-report measure that assesses wartime stressors experienced by service members. The total CES score (ranging 0 to 41 ) is calculated by using a sum of weighted scores, which can be classified into one of five categories of combat exposure ranging from "light" to "heavy." This scale rates cumulative combat exposure and is highly predictive of PTSD, pain and injury, TBI, depression, and other behavioral sequellae. ${ }^{47}$

$D S I$. The DSI is an adaptation of the Neurobehavioral Symptom Inventory-22 (NSI), with six additional questions assessing anger and distress adapted for a deployment context. Consistent with others, ${ }^{48}$ factor analysis revealed factors referred to as post-concussive symptom subscales in the current analysis: Neurocognitive (worsening focus, concentration, memory), Sensory (alterations in sensitivity to light, sound, smell), Somatic (increased pain, sleep, discomfort), and Vestibular (difficulties with balance or feeling dizzy), as well as total score. Because emotional complaints are better assessed through other measures included in the battery, they are not included in the current analysis of the DSI.

Insomnia Screening Index ${ }^{b}$ (ISI). A five-item scale evaluating perceived insomnia severity and sleep habits. Each item is rated on a five-point scale (0-4). The total score ranges 0 to 28 , and higher scores indicate more severe insomnia. A cutoff score of 10 has been shown to indicate insomnia. ${ }^{49}$

Pittsburgh Sleep Quality Index ${ }^{C}$ (PSQI). Nineteen selfrated items and 5 partner-rated items, which measure sleep quality during the previous month. This scale differentiates "good" from "poor" sleepers based on seven areas: subjective sleep quality, sleep latency, sleep duration, habitual sleep efficiency, sleep disturbances, use of sleeping medication, and daytime dysfunction over the last month. This scale is the most widely used sensitive and specific self-report measure for insomnia. A score above 6 indicates a "poor" sleeper. ${ }^{50}$

Demographics and background questionnaire. Service members were asked about age, gender, rank, deployment history.

Concussion questions. Based on the Post-deployment Health Assessment used for all deployed personnel, service members were asked about their history of concussion, including number of lifetime concussions, when their most recent concussion occurred, the immediate effects of the concussion on their cognitive status (dazed and confused, loss of memory, loss of consciousness), and current post-concussive symptoms.

\section{Hypotheses}

The relationship of recency and number of lifetime concussions on emotional distress, post-concussive symptoms, and neurocognitive functioning was examined. It was predicted that recency of last concussion and number of lifetime concussion would be negatively associated with emotional distress, post-concussive symptoms, and neurocognitive functioning, and further that concussion uniquely contributes to these factors independent of PTSD (PCL-M) or depression (PHQ-8) scores or deployment factors (time since deployment, CES).

\section{Planned analyses}

IBM SPSS v20.0 was used to calculate power and conduct all analyses. Sample size was initially determined from a power estimate of the differences between two groups (concussed - not concussed) to find at least a small effect size in SRT or PCL, based on the expected presence of at least $15 \%$ reported concussion, $15 \%$ PCL-M scores $>50$, and 15\% PHQ > 10 in those recently returned from a recent combat deployment. Power was also calculated based on stability of measures and expected standard errors determined in the Phase 1 pilot study. ${ }^{41}$

Descriptive reporting includes mean correct responses (Mean), $\mathrm{SD}$, percent correct (\%Correct), and TP for all neurocognitive scores; mean and SD for self-report psychological scores, and mean or number of cases and SD for age, sex, and number and recency of concussions. TP was used for analyses of interest for all cognitive tests, except for GNG and CDD where \%Correct is the metric of relevance.

The effects of recency of concussion and number of lifetime concussions on neurocognitive, emotional, and post-concussive scores are examined first with a univariate General Linear Model on continuous variables. Generalized Linear Modeling (with Wald statistic and Robust Estimator) was used to confirm significance when groups were associated with unequal variances per the Levine test of homogeneity. Pairwise comparisons between type of deployment and number of concussions using the Bonferroni correction were used to adjust for type-I error. PTSD (PCL-M), depression (PHQ-8), deployment history (never, recently within 6 months, and previously-longer than 6 months ago), and combat exposure (CES) scores were used as covariates to determine the unique contribution of concussion to emotional, post-concussive, and neurocognitive measures. PCL-M and PHQ-8 scores were not used as covariates when they were the outcome under investigation.

Logistic Regression was used to determine the odds ratios (OR) for the contribution of concussion to clinical cutoff scores for emotional measures (PCL-M > 49; PHQ-8 > 10; DSI-Anger > 1 $\mathrm{SD})$, and for neurocognitive functioning scores more than one SD 
from the mean. PCL-M, PHQ-8, deployment history, and CES covariates are included in these analyses as well unless the covariate is the outcome measure of interest (PCL-M, PHQ-8). Effect sizes are reported as partial eta ${ }^{2}\left(\eta_{\mathrm{p}}^{2}\right)$ for analysis of variance and ORs for Logistic Regression. Description of effect sizes as small, medium, and large is based on the Cohen interpretation. ${ }^{51}$ Because this is a single period analysis, data will be analyzed for the exact number of subjects who took the tests in the analysis without extrapolating for missing data.

\section{Results}

The total sample size consisted of 646 U.S. Marines with an average age of 22.7 years $(\mathrm{SD}=2.7)$, including 18 females. Because the chain of command was asked not to be present, almost all service members were junior enlisted (E2-E4). There were 234 service members who had never been deployed, 98 who were previously deployed (more than 1 year before assessment) and 314, all men, who were recently deployed (returning from combat deployment in Afghanistan within 3-6 months of testing). Of the 646 service members who were administered the assessment tool, 369 received the Standard Battery and 227 were administered the Rapid or Brief Battery. Because the Rapid and Brief Batteries are contained within the Standard Battery, calculations are based on $n=419$ involving measures of PCL-M, PSQI, DSI, SPD, CDS, CDD, and STN, and 646 for all other measures (CES, PHQ-8, SRT, PRT, GNG).

Of the entire sample, 25\%reported having been previously concussed at some point in their lifetime at least once, $7 \%$ reported two previous concussions, and $9 \%$ reported three or more times. Deployment status (never, previous, recent) and CES scores were associated with number and recency of concussions, PCL-M, PHQ-8; DSI-Anger, DSI-Total, PSQI, and the majority of the neurocognitive tests with moderate to large effect sizes. Therefore, deployment status and CES were included as covariates in all analyses. PCL-M and PHQ-8 are also included whenever they were not the outcome variables of interest.

\section{Effects of concussion on emotional symptoms}

Despite including covariates, having ever had one or more concussions was associated with PCL-M scores $(\mathrm{F}=15.55$, $\left.p<0.000, \quad \eta_{\mathrm{p}}^{2}=0.034\right), \quad$ PHQ-8 scores $(\mathrm{F}=5.38, \quad p<0.021$, $\left.\eta_{\mathrm{p}}^{2}=0.021\right)$, and DSI-Anger $\left(\mathrm{F}=9.67, \quad p<0.002, \eta_{\mathrm{p}}^{2}=0.023\right)$ compared with never having received a concussion. This was likely because of the presence of multiple concussions, however, because having had only one concussion was not associated with emotional distress greater than having no concussions. Recency of concussion was significant for PCL-M scores $\left(\mathrm{F}=9.93, p<0.000, \eta_{\mathrm{p}}^{2}=0.046\right)$; PHQ-8 scores $\left(\mathrm{F}=6.67, p<0.001, \eta_{\mathrm{p}}^{2}=0.031\right)$; and DSI-Anger $\left(\mathrm{F}=10.0, p<0.000 ; \eta_{\mathrm{p}}^{2}=0.055\right)$. Multiple concussions was significant for PCL-M $\left(\mathrm{F}=7.62, p<.0000, \eta_{\mathrm{p}}^{2}=0.053\right)$, PHQ-8 $\left(\mathrm{F}=4.54, \quad p<0.004, \quad \eta_{\mathrm{p}}^{2}=0.032\right)$, and DSI-Anger $\quad(\mathrm{F}=5.79$, $\left.p<0.001, \eta_{\mathrm{p}}^{2}=0.041\right)$.

Bonferoni corrected pairwise comparisons showed that a recent concussion was associated with more distress than distant concussion, and three or more lifetime concussions were associated with more distress than none or one concussion (at least $p<0.05$ in all cases). Two lifetime concussions were not significantly different from zero or one, or from three concussions.

No interaction between recency and number of concussions was found for either PHQ-8, PCL-M, or DSI-Anger, although those who reported having three or more lifetime concussions with the most recent within the past 6 months averaged a notably higher score $(\mathrm{PHQ}=11 ; \mathrm{PCL}=44 ;$ DSI-Anger $=5.5)$ compared with those without a history of concussion $(\mathrm{PHQ}=5$; $\mathrm{PCL}=31$; DSIAnger $=1.5$ ). The lack of statistical significance for these analyses was likely because of low sample sizes for those who were recently concussed and had multiple concussions; power was far too low to detect a significant difference (observed power was between 0.10 to 0.16).

Binary Logistic Regression with forward stepwise Wald model to eliminate shared variance and including covariates was significant for three versus zero or one lifetime concussions predicting PCL $>50$ (Wald $=22.11, p<0.000, \mathrm{OR}=2.48$, confidence interval [CI]: 1.70-3.63); PHQ $>10$ (Wald $=4.88, p<0.027, \mathrm{OR}=2.19, \mathrm{CI}$ : 1.09-4.40), and DSI-Anger $>1$ SD (Wald $=10.15, p<0.001$, $\mathrm{OR}=4.36$, CI: $1.76-10.80$ ).

Thus, the presence of at least one earlier concussion, independent of deployment and CES, was associated with emotional distress, with small effect sizes (Table 1). Multiple and recent concussions, independent of covariates, were associated with emotional distress with stronger effect sizes, and three or more lifetime concussions more than doubled the odds of reaching clinical cutoff scores for PTSD and depression, and had four times the odds of anger problems.

\section{Effects of concussion on post-concussive symptoms}

To explore the relationship of concussion to reporting of persistent post-concussive symptoms, continuous variables of the DSI subscales and sleep issues from the PSQI were analyzed incorporating covariates of previous deployment, CES, PCL-M, and PHQ-8. The presence of at least one previous concussion was not related to DSI-Cognitive symptoms, DSI-Sensory symptoms, DSI-Vestibular, or DSI-Total, but was associated with DSI-Somatic symptoms with a very small effect size ( $\mathrm{F}=5.67, p<0.018$, $\left.\eta_{\mathrm{p}}^{2}=0.014\right)$, and with sleep problems on the PSQI $(\mathrm{F}=13.93$, $\left.p<0.000, \eta_{\mathrm{p}}^{2}=0.038\right)$. Planned comparisons of number of concussions using the Bonferroni correction, however, showed that DSI-Somatic and insomnia findings were likely because of the presence of multiple concussions, because only one previous concussion did not significantly vary from no history of concussions.

Recency of concussion was associated with DSI-Sensory $\left(\mathrm{F}=5.56, p<0.004, \eta_{\mathrm{p}}^{2}=0.026\right)$, DSI-Somatic $(\mathrm{F}=5.00, p<0.002$, $\left.\eta_{\mathrm{p}}^{2}=0.024\right)$, DSI-Vestibular $\left(\mathrm{F}=6.45, p<0.002, \eta_{\mathrm{p}}^{2}=0.030\right)$, and PSQI $\left(\mathrm{F}=6.51, p<0.002, \eta_{\mathrm{p}}^{2}=0.036\right)$, but not with DSI-Cognitive or DSI-Total. Number of concussions was associated with DSISomatic $\quad\left(\mathrm{F}=3.01, \quad p<0.027, \quad \eta_{\mathrm{p}}^{2}=0.022\right), \quad$ DSI-Vestibular $\left(\mathrm{F}=2.67, p<0.047 ; \eta_{\mathrm{p}}^{2}=0.019\right)$, and sleep disturbance (PSQI, $\left.\mathrm{F}=5.42, p<0.001, \eta_{\mathrm{p}}^{2}=0.044\right)$, but not with DSI-Cognitive, DSISensory, or DSI-Total. Three or more concussions compared with none or one previous concussion was associated with DSI-Sensory $\left(\mathrm{F}=8.56, p<0.004, \eta_{\mathrm{p}}^{2}=0.022\right)$, DSI-Somatic $(\mathrm{F}=8.75, p<0.023$, $\left.\eta_{\mathrm{p}}^{2}=.023\right)$, and DSI-Vestibular $\left(\mathrm{F}=8.65, p<0.003, \eta_{\mathrm{p}}^{2}=0.022\right)$, but not for DSI-Cognitive, DSI-Total or insomnia. Two previous concussions were not significantly different from zero or one concussion in any post-concussive symptom outcome, except for insomnia $(p<0.004)$ (Table 2).

A two-way ANCOVA with independent variables Recency of Concussion and Number of Concussions, including Previous Deployment, CES, PCL-M, and PHQ-8 as covariates, found significant or marginally significant interactions for DSI-Cognitive $(\mathrm{F}=4.25$, $\left.\mathrm{df}=2,406, p<0.021, \eta_{\mathrm{p}}^{2}=0.021\right)$, DSI-Sensory $(\mathrm{F}=2.64, \mathrm{df}=2,406$, $\left.p<0.072, \eta_{\mathrm{p}}^{2}=0.013\right)$, DSI-Somatic $(\mathrm{F}=2.95, \mathrm{df}=2,406, p=0.054$, 
Table 1. Influence of Concussion History on Emotional Tests

\begin{tabular}{|c|c|c|c|c|c|c|c|}
\hline & \multicolumn{7}{|c|}{ Emotional tests (with all covariates included) } \\
\hline & \multirow[b]{2}{*}{$N$} & \multicolumn{2}{|c|}{$P C L-M$} & \multicolumn{2}{|c|}{$P H Q-8$} & \multicolumn{2}{|c|}{ DSI-Anger } \\
\hline & & Mean $(S D)$ & $\mathrm{p}$ value $(E S)$ & Mean $(S D)$ & $\mathrm{p}$ value $(E S)$ & Mean $(S D)$ & $\mathrm{p}$ value $(E S)$ \\
\hline \multicolumn{8}{|c|}{ Any past concussion: } \\
\hline No & 300 & $27.7(11.8)$ & & $4.8(4.9)$ & & $1.6(2.2)$ & \\
\hline Yes & 116 & $34.2(15.4)$ & $0.000(\mathrm{~m})$ & $6.3(5.3)$ & $0.021(\mathrm{~s})^{*}$ & $2.6(2.2)$ & $0.002(\mathrm{~s})^{*}$ \\
\hline Never & 305 & $27.5(11.7)$ & & $4.7(4.9)$ & & $1.46(2.1)$ & \\
\hline$>6$ mos. ago & 98 & $33.6(14.8)$ & & $6.0(5.1)$ & & $2.27(2.4)$ & \\
\hline$<6$ mos. ago & 15 & $42.1(17.6)$ & $0.000(\mathrm{~m})$ & $9.9(5.5)$ & $0.001(\mathrm{~s})^{*}$ & $4.31(3.3)$ & $0.000(\mathrm{~m})^{*}$ \\
\hline 0 & 305 & $27.5(11.7)$ & & $4.7(4.9)$ & & $1.6(2.2)$ & \\
\hline 1 & 36 & $32.2(13.4)$ & & $5.7(4.0)$ & & $2.0(2.5)$ & \\
\hline 2 & 33 & $31.2(14.6)$ & & $5.3(5.1)$ & & $2.4(2.9)$ & \\
\hline $3+$ & 43 & $39.4(16.9)$ & $0.000(\mathrm{~m})$ & $8.3(5.4)$ & $0.004(\mathrm{~s}) *$ & $3.5(2.7)$ & $0.001(\mathrm{~m})$ \\
\hline $0-1$ vs. $3+>$ & 387 & & $0.000 \mathrm{OR}=2.48$ & & $\begin{array}{l}0.027 \mathrm{OR}=2.19 \\
{[\mathrm{PHO}-8>101}\end{array}$ & & $0.001 \mathrm{OR}=4.36$ \\
\hline
\end{tabular}

PCL-M, Post-traumatic Symptom Disorder Check List, military version; PHQ-8 Primary Care Health Questionnaire; DSI-Anger, Deployment Stress Inventory; SD, standard deviation; ES, effect size; OR, odds ratio.

*Significant $(p<0.001)$ with a moderate to large effect size before including covariates of previous deployment, CES, PCL-M, and PHQ-8.

The influence of any previous concussion, recency of most recent concussion (less than or greater than 6 months since the most recent concussion), number of Lifetime Concussions ( $0,1,2,3$, or more) and three or more versus zero or one concussions on emotional and post-concussive symptom reporting, showing mean and standard deviation (SD). General Linear Model (ANCOVA) results for significance level ( $p$ value) and effect size (ESsmall [s], medium [m], or large [1]) using partial eta-squared effect size $\left(\eta^{2}\right.$ p $)$ are based on the throughput, with Combat Exposure Survey, Deployment, PCL-M, and PHQ-8 serving as covariates (except when the covariate is itself the dependent variable). Bivariate Logistic Regression reports Wald for unique contributions and odds ratio for three or more versus zero or one lifetime concussions.

$\left.\eta_{\mathrm{p}}^{2}=0.014\right)$, DSI-Total $\left(\mathrm{F}=3.02, \mathrm{df}=2,406 ; p<0.05, \eta_{\mathrm{p}}^{2}=0.015\right)$, but not DSI-Vestibular or PSQI, with those who had three or more concussions with the most recent concussion within 6 months reporting more distress than those who had none or one concussion in the more distant past. ES were small for all analyses, likely because of insufficient power.

Binary Logistic Forward Stepwise Wald Regression was used to determine the influence of three or more concussions compared with zero or one concussion on DSI scales being one SD above the mean. Results showed three or more concussions predicting DSISensory (Wald $=7.42, p=0.006, \mathrm{OR}=1.81, \mathrm{CI}: 1.15-2.76$ ) and DSI-Vestibular (Wald $=4.24, p=0.04$, OR $=2.57$, CI: $1.05-6: 74$ ), but not DSI-Cognitive, DSI-Somatic, DSI-Total, or PSQI when all covariates were included. Without covariates, all DSI subscales were significant with at least moderate ES.

In general, independent of deployment, CES, PCL-M, and PHQ-8 scores, the presence of a previous concussion was not related to post-concussive reporting, with the exception of more insomnia.

Table 2. Influence of Concussion History on Post-Concussive Tests

\begin{tabular}{|c|c|c|c|c|c|c|c|c|c|c|c|c|c|c|}
\hline & \multirow[b]{3}{*}{$N$} & \multicolumn{13}{|c|}{ Post-concussive tests (with all covariates included) } \\
\hline & & \multicolumn{2}{|c|}{ DSI-Cognitive } & \multicolumn{2}{|c|}{ DSI-Sensory } & \multicolumn{2}{|c|}{ DSI-Somatic } & \multicolumn{2}{|c|}{ DSI-Vestibular } & \multicolumn{2}{|c|}{ DSI-Total } & \multicolumn{3}{|c|}{$P S Q-I$} \\
\hline & & $M(S D)$ & $\mathrm{p}(E S)$ & $M(S D)$ & $\mathrm{p}(E S)$ & $M(S D)$ & $\mathrm{p}(E S)$ & $M(S D)$ & $\mathrm{p}(E S)$ & $M(S D)$ & $\mathrm{p}(E S)$ & $N$ & $M(S D)$ & $\mathrm{p}(E S)$ \\
\hline \multicolumn{15}{|c|}{ Any past concussion: } \\
\hline No & 300 & $.38(.47)$ & & $.13(.25)$ & & $.36(.33)$ & & $.15(.31)$ & & $.37(.36)$ & & 256 & $5.3(3.2)$ & \\
\hline Yes & 116 & $.57(.55)$ & n.s.* & $.25(.40)$ & n.s. ${ }^{*}$ & $.55(.44)$ & $.018(\mathrm{~s})^{*}$ & $.30(.47)$ & n.s.* & $.56(.46)$ & n.s. ${ }^{*}$ & 99 & $7.8(4.1)$ & $.000(\mathrm{~m})$ \\
\hline Never & 305 & $.38(.46)$ & & $.12(.25)$ & & $.36(33)$ & & $.15(.30)$ & & $.34(.35)$ & & 257 & $5.3(3.2)$ & \\
\hline$>6$ mos. ago & 137 & $.56(.52)$ & & $.21(.35)$ & & $.52(.41)$ & & $.25(.43)$ & & $.51(.42)$ & & 84 & $7.6(4.1)$ & \\
\hline$<6$ mos. ago & 16 & $.76(.70)$ & n.s.* & $.53(.57)$ & $.004(\mathrm{~s}) *$ & $.86(.37)$ & $.007(\mathrm{~s})^{*}$ & $.59(.36)$ & $.002(\mathrm{~s})^{*}$ & $.82(.53)$ & n.s. ${ }^{*}$ & 15 & $8.7(3.9)$ & $.002(\mathrm{~m})$ \\
\hline 0 & 305 & $.38(.46)$ & & $.12(.25)$ & & $.36(.33)$ & & $.15(.30)$ & & $.37(.37)$ & & 257 & $5.3(3.2)$ & \\
\hline 1 & 36 & $.48(.47)$ & & $.19(.30)$ & & $.46(.39)$ & & $.21(.38)$ & & $.47(.40)$ & & 28 & $7.4(.4 .0)$ & \\
\hline 2 & 33 & $.57(.55)$ & & $.18(.35)$ & & $.50(.44)$ & & $.21(.37)$ & & $.53(.46)$ & & 29 & $7.8(4.0)$ & \\
\hline $3+$ & 43 & $.69(.58)$ & n.s.* & $.37(.47)$ & n.s.* & $.71(.43)$ & $.027(\mathrm{~s})^{*}$ & $.45(.57)$ & $.047(\mathrm{~s})^{*}$ & $.70(.48)$ & n.s.* & 43 & $8.0(.4 .2)$ & $.001(\mathrm{~m})$ \\
\hline $0-1$ & 341 & $.38(.46)$ & & $.13(.25)$ & & $.37(.33)$ & & $.15(.31)$ & & $.38(.37)$ & & 285 & $5.5(3.3)$ & \\
\hline Vs.3+ & 43 & $.71(.49)$ & n.s.* & $.38(.47)$ & $.004(\mathrm{~s}) *$ & $.71(.43)$ & $.003(\mathrm{~s})^{*}$ & $.46(.57)$ & $.003(\mathrm{~s})^{*}$ & $.71(.40)$ & n.s. $*$ & 43 & $8.0(4.3)$ & n.s. $*$ \\
\hline
\end{tabular}

DSI, Deployment Stress Inventory ; PSQI, Pittsburg Sleep Quality Inventory ; SD, standard deviation; ES, effect size.

* Significant $(p<0.001)$ with a moderate to large effect size before including covariates of previous deployment, Combat Exposure Survey, PostTraumatic Symptom Disorder Check List, military, and Primary Care Health Questionnaire-8.

The influence of any previous concussion, recency of most recent concussion (less than or greater than 6 months since the most recent concussion), number of Lifetime Concussions $(0,1,2,3$, or more), and three or more versus zero or one concussions on emotional and post-concussive symptom reporting, showing mean $(\mathrm{M})$, standard deviation $(\mathrm{SD}), p$ value $(p)$, and effect size (ES- small [s], medium [m], or large [1]). 
Recency of concussion, number of concussions (especially having had three or more lifetime concussions), as well as the interaction between number and recency of concussions, however, was associated with worse post-concussive symptoms reporting. ES were large when covariates were not included, suggesting the synergistic effects of these covariates with concussion on post-concussive symptom reporting.

\section{Effects of concussion on neurocognitive functioning}

The effects of concussion on neurocognitive functioning were analyzed with the inclusion of covariates including previous deployment, CES, PCL-M, and PHQ-8. If significance was marginal, analysis was conducted for PCL-M and PHQ-8 covariates only or with no covariates and reported accordingly to determine the relative factors influencing neurocognitive functioning. Therefore, reported significance includes all covariates, unless otherwise indicated. Summary of findings, including Means, SD, \%Correct, and TP along with significance for the relevant covariates are reported in Table 3. The most relevant metric for analysis, TP for SRT, PRT, SPD, CDS, and STN, and \%Correct for GNG and CDD are used for analysis, below.

Single concussion. Having ever experienced a previous concussion $(\mathrm{Y} / \mathrm{N})$ was associated with SRT-TP $(\mathrm{F}=7.11, p=0.008$, $\left.\eta_{\mathrm{p}}^{2}=0.011\right)$ and PRT-TP $\left(\mathrm{F}=5.82, p=0.016, \eta_{\mathrm{p}}^{2}=0.009\right)$ but only without covariates included). GNG-\%, CDS-TP, SPD-TP, STN$\mathrm{TP}$, and CDD-TP were not significant, even without inclusion of any covariates. In summary, having a previous concussion $(\mathrm{Y} / \mathrm{N})$ was not associated with neurocognitive outcomes when covariates for PTSD, PHQ, and deployment experience were taken into account.

Recency of concussion. The effects of a concussion within 6 months compared with previously or never concussed was significant for SRT-TP $\left(\mathrm{F}=4.48, p=0.012, \eta_{\mathrm{p}}^{2}=0.014\right)$ and PRT-TP $\left(\mathrm{F}=4.81, p=0.008, \eta_{\mathrm{p}}^{2}=0.015\right)$, but only when no covariates were included. CDS-TP, GNG-\%, SPD-TP, STN-TP, and CDD-\% were not significant, even without including covariates. In summary, the effects of recency of concussion were detected by SRT and PRT only when no covariates were included, and not at all by other neurocognitive measures, possibly because of the low numbers of service members who reported a concussion within the previous 6 months. Indeed, cell sizes ranging between 11 and 16 produced power below 0.30 for these analyses.

Multiple lifetime concussions. Multiple concussions (0, 1, 2, 3 , or more) were associated with SRT-TP ( $\mathrm{F}=2.94, p=0.03$, $\eta_{\mathrm{p}}^{2}=0.021$, with only PCL-M and PHQ-8 as covariates), marginally for PRT-TP $\left(\mathrm{F}=2.57, p=0.053, \eta_{\mathrm{p}}^{2}=0.012\right.$, without covariates), GNG- $\%\left(F=3.15, p=0.025, \eta^{2} \mathrm{p}=0.015\right.$, without covariates $)$, and CDS-TP $\left(\mathrm{F}=2.68, \mathrm{p}=0.046, \eta_{\mathrm{p}}^{2}=0.019\right.$, without covariates $)$. CDS-\% SPD-TP, SPD-TP, and CDD-\% were not significant, even without covariates. Because of concerns that those receiving only Rapid or Brief batteries may not have been equivalent to those receiving Standard, similar analyses were conducted with Brief subjects only, using the same covariates except substituting the PCPTSD taken by Brief subjects instead of the PCL-M.

GLM ANCOVA with covariates entered together showed that results were similar for this subsample: Number of Concussions, but not Recency of Concussion, was associated with SRT-TP, PRTTP, GNG-\%, and CDS-TP without covariates. In summary, several of the neurocognitive tests requiring simpler processing responses were positive for multiple concussion without covariates included. In all cases, results were in the expected direction; however, when all covariates were included, these trends were eliminated.

$3+$ Lifetime concussions. Because there was no significant difference between none and one concussions, and most often not even with two concussions, and the largest difference across outcomes was from having three or more lifetime concussions, additional analysis was conducted on three or more concussions $(3+)$ compared with none or one concussion (0-1). A significant difference was detected, incorporating all covariates, for SRT-TP $\left(\mathrm{F}=6.57, p=0.011, \eta_{\mathrm{p}}^{2}=0.017\right)$ and GNG-\% $(\mathrm{F}=4.43, p=0.036$, $\left.\eta_{\mathrm{p}}^{2}=0.012\right)$ incorporating all covariates, PRT-TP $(\mathrm{F}=3.76$, $p=0.05, \eta_{\mathrm{p}}^{2}=0.010$, with PCL and PHQ8 covariates), and CDS-TP $\left(\mathrm{F}=6.16, p=0.013, \eta_{\mathrm{p}}^{2}=0.016\right)$ with the inclusion of all covariates. SPD-TP, STN-TP and CDD-\% were not significant, even without the inclusion of covariates. No interaction of recency of concussion by $3+$ concussions was found. In summary, those who reported three or more lifetime concussions were worse on neurocognitive tasks requiring simple attention and simple discrimination skills, including SRT-TP, GNG-\%, and CDS-TP. The effects of three or more concussions were not detected by SPD-TP or the memory tests CDD-\% and STN-\%.

Finally, a Binary Logistic Wald Forward Stepwise Regression with all four covariates was conducted to examine the effect of three or more compared with none or one lifetime concussions on neurocognitive functioning further than one SD from the mean. A z-score of $<1$ SD was used because Receiver Operating Characteristic Curve Analysis revealed that three or more previous concussions predicted SRT-TP $<1$ SD below the mean with a sensitivity of 0.91 and specificity of 0.96 , and an overall accuracy of $82 \%(p<0.03)$. Analysis was limited to those tests shown above to be sensitive to impairment: SRT-TP, PRT-TP, and \%GNG using a cutoff of less than one SD from the mean, and including covariates scores on PCL-M, PHQ-8, CES, and Previous Deployment status.

As presented in Table 4, three or more lifetime concussions predicted neurocognitive decrement in SRT-TP (Wald $=5.47$, $p=0.019, \quad \mathrm{OR}=2.17, \quad \mathrm{CI}: 1.16-5.24), \quad$ PRT-TP $\quad(\mathrm{Wald}=4.11$, $p<0.043, \quad \mathrm{OR}=1.96, \quad \mathrm{CI}: \quad 1.02-3.77), \quad$ and $\mathrm{GNG}-\%$ Correct (Wald $=4.90, p<0.027, \mathrm{OR}=2.82$ : CI: 1.13-7.06). From these results, it appears that simple measures of neurocognitive functioning are sensitive to the effects of three or more concussions, independent of emotional and deployment covariates.

\section{Discussion}

Given the spike in patients presenting with concussions to emergency departments over the past 5 years, thought to be because of increased public awareness of the problem, understanding persistent symptoms associated with concussion is of growing importance. ${ }^{52}$ Toward that end, this study attempted to determine what factors are related to PPCS, especially disentangling deployment factors from emotional factors from concussion type. PPCS was examined in terms of emotional distress (PTSD, depression, and anger symptoms), post-concussive symptoms reporting (cognitive, sensory, somatic, vestibular, and insomnia), and neurocognitive functioning across a wide range of domains of speed and accuracy.

This research was distinct from earlier studies that recruited patients presenting to a clinic and evaluated a narrower range of 
Table 3. Influence of Concussion History on Cognitive Tests

\begin{tabular}{|c|c|c|c|c|}
\hline \multicolumn{5}{|c|}{ Cognitive tests (sig. with all covariates included or none as indicated) } \\
\hline Tests & $N$ & Mean $R T(S D)$ sig. & $\%$ Correct (SD) sig. & $T P(S D)$ sig. \\
\hline \multicolumn{5}{|l|}{$S R T$} \\
\hline \multicolumn{5}{|c|}{ Any past concussion: } \\
\hline No & 476 & $332.1(57.5)$ & $.990(.03)$ & $193.4(29.6)$ \\
\hline Yes & 167 & $350.2(83.6) *$ none & $.981(.04) *$ none & $185.7(38.1) *$ none \\
\hline Never & 494 & $332.9(59.0)$ & $.990(.03)$ & $193.1(29.9)$ \\
\hline$>6$ mos. ago & 136 & $347.7(82.7)$ & $.982(.04)$ & $186.6(37.8)$ \\
\hline$<6$ mos. ago & 14 & $375.0(17.5) *$ none & $.975(.06) *$ none & $173.3(42.7) *$ none \\
\hline 0 & 305 & $336.0(60.2)$ & $.999(.04)$ & $190.7(30.6)$ \\
\hline 1 & 35 & $329.6(60.7)$ & $.995(.01)$ & $195.9(20.3)$ \\
\hline 2 & 33 & $349.5(83.9)$ & $.980(.05)$ & $184.7(39.0)$ \\
\hline $3+$ & 42 & $377.9(107.3) *$ all & $.964(.05)^{*}$ all & $173.3(47.0) * \mathrm{PCL} / \mathrm{PHQ}$ \\
\hline $0-1$ & 340 & $335.3(60.2)$ & $.999(.03)$ & $191.9(30.5)$ \\
\hline vs $3+$ & 42 & $377.9(107.3)^{* * * a a l l}$ & $.964(.06)^{* * * a}$ all & $173.3(47.0)^{* *}$ all \\
\hline \multicolumn{5}{|l|}{$P R T$} \\
\hline \multicolumn{5}{|c|}{ Any past concussion: } \\
\hline No & 475 & $629.0(101.1)$ & $.985(.02)$ & $101.5(14.3)$ \\
\hline Yes & 168 & $659.1(152.6) *$ none & $.977(.03) *$ none & $98.3(16.5) *$ none \\
\hline Never & 493 & $643.7(106.6)$ & $.984(.02)$ & $101.5(14.2)$ \\
\hline$>6$ mos. ago & 138 & $665.5(156.4)$ & $.979(.03)$ & $98.6(16.0)$ \\
\hline$<6$ mos. ago & 15 & $717.5(263.3)^{* *}$ none & $.964(.05)^{* *}$ none & $91.6(22.4) * *$ none \\
\hline 0 & 305 & $643.7(106.6)$ & $.984(.02)$ & $99.8(14.8)$ \\
\hline 1 & 36 & $645.3(119.5)$ & $.984(.02)$ & $101.1(16.0)$ \\
\hline 2 & 32 & $651.27(93.3)$ & $.987(.02)$ & $98.3(12.7)$ \\
\hline $3+$ & 42 & $709.6(242.5) *$ none & $.966(.03)^{* * * a l l}$ & $94.1(21.9) *$ none \\
\hline $0-1$ & 341 & $643.9(107.9)$ & $.985(.02)$ & $99.9(14.9)$ \\
\hline vs $3+$ & 42 & $709.6(242.5)^{*}$ all & $.964(.03)^{* * * a a l l}$ & $93.8(21.7) * \mathrm{PCL} / \mathrm{PHQ}$ \\
\hline \multicolumn{5}{|l|}{$G N G$} \\
\hline \multicolumn{5}{|c|}{ Any past concussion: } \\
\hline No & 462 & $99.6(14.8)$ & $.990(.03)$ & $118.3(19.1)$ \\
\hline Yes & 162 & 97.7 (17.7) n.s. & .985 (.032) n.s. & 116.8 (20.4) n.s. \\
\hline Never & 479 & $538.8(101.7)$ & $.990(.03)$ & $118.4(19.0)$ \\
\hline$>6$ mos. ago & 131 & $555.0(135.4)$ & $.986(.03)$ & $117.0(20.3)$ \\
\hline$<6$ mos. ago & 15 & 568.5 (118.9) n.s. & $.976(.05)$ n.s. & 111.3 (23.7) n.s. \\
\hline 0 & 478 & $538.8(101.7)$ & $.990(.03)$ & $118.4(19.0)$ \\
\hline 1 & 51 & $556.5(126.4)$ & $.983(.02)$ & $116.6(19.7)$ \\
\hline 2 & 37 & $552.3(109.6)$ & $.984(.03)$ & $115.9(20.2)$ \\
\hline $3+$ & 58 & 559.9 (110.1) n.s. & $.979(.04) *$ all & 116.5 (22.1) n.s. \\
\hline $0-1$ & 529 & $540.5(104.4)$ & $.989(.03)$ & $118.2(19.1)$ \\
\hline vs $3+$ & 58 & $559.0(154.0)$ n.s. & $.975(.05) *$ all & 116.5 (22.1) n.s. \\
\hline \multicolumn{5}{|l|}{$C D S$} \\
\hline \multicolumn{5}{|c|}{ Any past concussion: } \\
\hline No & 302 & $1346.4(243.6)$ & $.966(.04)$ & $46.9(9.4)$ \\
\hline Yes & 115 & 1394.9 (296.8) n.s. & $.955(.05) *$ none & 45.1 (10.5) n.s. \\
\hline Never & 307 & $1343.9(243.3)$ & $.966(.04)$ & $47.0(9.4)$ \\
\hline$>6$ mos. ago & 96 & $1388.5(272.3)$ & $.958(.04)$ & $45.2(9.9)$ \\
\hline$<6$ mos. ago & 15 & $1500.7(422.4) *$ none & $.936(.06) *$ none & 42.4 (9.7) n.s. \\
\hline 0 & 305 & $1344.0(243.3)$ & $.966(.04)$ & $47.0(9.4)$ \\
\hline 1 & 36 & $1332.6(288.8)$ & $.960(.04)$ & $47.4(10.3)$ \\
\hline 2 & 32 & $1435.7(298.0)$ & $.952(.05)$ & $44.1(11.1)$ \\
\hline $3+$ & 43 & $1439.3(299.3) *$ none & .942 (.05) n.s. & $43.2(9.7) *$ none \\
\hline $0-1$ & 341 & $1342.7(248.0)$ & $.966(.04)$ & $47.1(9.5)$ \\
\hline vs $3+$ & 43 & $1439.4(255.6) *$ none & $.952(.05)$.n.s. & $43.2(9.7) *$ all \\
\hline
\end{tabular}

SRT Simple Reaction Time; RT, Reaction Time; SD, standard deviation; TP, throughput; PCL, Post-Traumatic Symptom Disorder Check List; PHQ, Primary Care Health Questionnaire; PRT, Procedural Reaction Time; GNG, Go-No-Go; CDS, Code Substitution Simultaneous.

TP is a measure of cognitive efficiency, based on both speed and accuracy. Higher values indicate better cognitive efficiency.

$* p<0.05, * * p<0.01, * * * p<0.005$ using Previous Deployment, Combat Exposure Survey (CES), PCL, PHQ as covariates.

Number of concussions ( $0,1,2,3$, or more) and Recency of Concussion (less than or greater than 6 months since the most recent concussion) reporting Mean Correct RT, SD, Percent Correct, TP. General Linear Model (ANCOVA), or Generalized Linear Modeling (for unequal variances) results for significance level with covariates are reported. Covariates are referred to as ALL (PCL/PHQ/CES/Deployment), PCL/PHQ (only), and none. Memory and spatial tests (Spatial Rotation Discrimination/ Sternberg Memory Test/ Code Substitution-Delayed Memory) were not significant, so are not included in the table. 
Table 4. Effect of Three or More Lifetime Concussions on Neurocognitive Functioning

\begin{tabular}{|c|c|c|c|c|c|c|}
\hline \multicolumn{7}{|c|}{ Variables in the equations } \\
\hline$S R T-T P$ & $B$ & S.E. & Wald & $d f$ & Sig. & $\operatorname{Exp}(B)$ \\
\hline \multicolumn{7}{|l|}{ Step $2^{\mathrm{b}}$} \\
\hline Conc_Count_01_v_3plus(1) & -.902 & .385 & 5.477 & 1 & .019 & 2.174 \\
\hline PCLOSCORE & -.027 & .010 & 7.053 & 1 & .008 & 1.027 \\
\hline Constant & 2.236 & .414 & 29.136 & 1 & .000 & 9.355 \\
\hline \multicolumn{7}{|c|}{$\begin{array}{l}\text { a. Variable(s) entered on step 1: PCLOSCORE. } \\
\text { b. Variable(s) entered on step 2: Conc_Count_01_v_3plus. }\end{array}$} \\
\hline$P R T-T P$ & $B$ & S.E. & Wald & $d f$ & Sig. & $\operatorname{Exp}(B)$ \\
\hline \multicolumn{7}{|l|}{ Step $1^{\mathrm{a}}$} \\
\hline Conc_Count_01_v_3plus(1) & .675 & .333 & 4.113 & 1 & .043 & 1.964 \\
\hline Constant & .048 & .166 & .084 & 1 & .772 & 1.049 \\
\hline \multicolumn{7}{|c|}{ a. Variable(s) entered on step 1: Conc_Count_01_v_3plus. } \\
\hline GNG-\%Correct & $B$ & S.E. & Wald & $d f$ & Sig. & $\operatorname{Exp}(B)$ \\
\hline \multicolumn{7}{|l|}{ Step $1^{\mathrm{a}}$} \\
\hline Conc_Count_01_v_3plus(1) & 1.037 & .468 & 4.901 & 1 & .027 & 2.819 \\
\hline Constant & -2.156 & .234 & 84.805 & 1 & .000 & .116 \\
\hline
\end{tabular}

a. Variable(s) entered on step 1: Conc_Count_01_v_3plus.

Binary Logistic Wald Forward Stepwise Regression examining the effect of three or more lifetime concussions on neurocognitive functioning: Simple Reaction Time Throughput (SRT-TP), Procedural Reaction Time Throughput (PRT-TP), and Go-No-Go \%Correct (\%GNG) using a cutoff of less than one standard deviation from the mean, and including covariates scores on Post-Traumatic Symptom Disorder Check List-Military; Primary Care Health Questionnaire; Combat Exposure Survey, and Previous Deployment status. Only final model step is presented.

outcomes in that it assessed a cohort of active duty US military service members who were fit for duty and participating in daily work activities, with assessment of previous deployment, combat exposure, emotional distress, post-concussive symptoms, and neurocognitive functioning to examine persistent effects of concussion. Further, by including previous deployment, combat exposure, PTSD, and depressive symptoms as covariates to determine the unique contribution of concussion, this approach was able to explore the theory that PPCS is because of emotional issues alone.

Results showed that recent deployment, higher CES, PCL-M, and PHQ8 each had an effect on concussion number and recency, emotional distress, and post-concussive symptom reporting, as well as for Attention-Discrimination type neurocognitive tasks, but not for memory-dependent tasks. The presence of a previous concussion as well as recency of concussion had an effect on emotional distress. The presence of a previous concussion was not related to post-concussive symptom reporting, with the exception of insomnia, nor to neurocognitive functioning. Recency and number of concussions, however, were associated with post-concussive symptom reporting, and number of concussions was related to Attention-Discrimination type neurocognitive functioning.

Having had three or more lifetime concussions was associated with the worst scores for depression, PTSD, anger, post-concussive sensory, somatic, and vestibular symptoms, and was predictive of the lowest performers on simple cognitive tasks. Although subjective cognitive complaints and insomnia symptoms are associated with three or more lifetime concussions with a moderate effect size, these associations were not sustained when deployment, CES, PTSD Sx, and Depressive Sx were considered as covariates. This suggests that persons with multiple concussions may complain of cognitive and insomnia symptoms, but at least in this sample, they appear to be primarily from emotional factors.
Our findings support earlier reports that deployment was associated with worsening neurocognitive $\mathrm{v}^{32,40}$ and emotional ${ }^{53}$ functioning. We also found support for previous research that depression and PTSD are strong predictors of post-concussive symptoms, including neuropsychological and self-reported postconcussive symptoms. ${ }^{18,20}$ In addition, findings in this study sample for the most part supported earlier research that failed to find the presence of a previous concussion to be related to post-concussive symptom reporting or a decrease in neurocognitive efficiency, once the contributions of deployment, combat exposure, PTSD, and depressive symptoms were removed.

The presence of previous concussion, however, independent of previous deployment or combat exposure, was associated with worse levels of PTSD, depression, and insomnia, all with moderate effect sizes. Moreover, the presence of three or more lifetime concussions was associated with a decrease in cognitive efficiency and an increase in post-concussive symptoms, independent of PTSD and depressive symptoms or likely diagnosis. Specifically, recency of concussion was associated with worse emotional and post-concussive symptoms, especially for those who had three lifetime concussions.

There was insufficient power to determine if having a concussion within the previous 6 months was a further contributor to cognitive functioning, but given that the effects of multiple concussion were consistently worse for those with a recent deployment, and the interaction of recency and number of concussions in other domains, the impact of recency of concussion on postconcussive symptoms is worthy of continued examination. Indeed, a recent study of active duty soldiers showed that recent concussion, independent of injury mechanism or combat exposure, is predictive of persistent post-concussive complaints. ${ }^{54}$

Thus, although these findings are consistent with research that failed to find independent evidence for the presence or absence of 
previous concussion, the evidence of recent and multiple concussion across a range of emotional distress, post-concussive symptom, and neurocognitive functioning is in contrast with other studies that failed to find a unique contribution for concussion across a wide range of persistent post-concussive symptoms. ${ }^{18,55}$ Possible reasons for this may include the failure of other studies to include both objective and subjective assessments of functioning, assessment of a wide range of PPCS including neurocognitive, selfreport emotional and somatic symptoms, and, most importantly, the distinction between single and multiple concussion, and its recency. Further, the assessment of deployment and combat exposure has rarely been used to tease out the specific effects of combat deployment from other factors influencing PPCS outcomes in active duty personnel. This may have implications for civilians as well in that severity of trauma exposure may need to be included in any assessment of PPCS.

Although we included previous deployment and CES as covariates, we wanted to insure that the results based on the entire sample were also seen in the recently deployed troops only (deployed within the previous 6 months). Analysis of the effects of three or more lifetime concussions in this subsample showed a similar pattern to what is reported with the entire sample on emotional and post-concussive symptoms as well as neurocognitive functioning.

Also of note, recently deployed service members in our sample had slower reaction times across several neurocognitive tests compared with never or previously deployed service members. Vasterling and coworkers, ${ }^{32}$ however, found post-deployed service members responded faster in several neuropsychological tests than they did pre-deployment, which they attributed to a hyperaroused nervous system. Perhaps this is because of differences in testing methods; we used an NCAT capable of assessing each response for speed and accuracy, whereas Vasterling used paper and pencil measures to determine overall speed. Moreover, these authors assessed service members sooner after deployment, when their nervous systems may have been in a different state than several months later. Certainly, more longitudinal and cross-sectional research on post-deployed service members is needed to shed light on neurocognitive performance after stressful deployments.

The fact that this neurobehavioral battery was generally sensitive to factors (despite that covariates often accounted for most of the variance) shows that such neurobehavioral batteries hold promise as a useful tool for detecting alterations in cognitive functioning from a variety of reasons, whether emotional, physical, or because of fatigue. It is noteworthy that those tests relying more on attention and simple discrimination (SRT, PRT, GNG, and CDS) were more sensitive to the effects of recency and number of lifetime concussions than were SPD or the memory-dependent tests (CDD, STN). This may be because of the increased time to answer these latter tasks along with the ability to rally compensatory effort and strategies. By contrast, the simpler tasks needed to be answered in a faster period and relied on more primitive processing skills, thus not permitting for increased effort or compensatory mechanisms to be used.

Based on these results, this study shows that the tests contained within this neurobehavioral battery, especially those relying on attention and simple discrimination, may be worthwhile administering to military members to determine how they are functioning so that early detection of suspected problems can aid in getting them the care they need. Although covariate analysis was conducted to demonstrate the unique contribution of concussion, PTSD, depression, and other factors influencing PPCS, it is important to appreciate that the combination of concussive and psy- chological factors are frequently co-occurring, likely enhancing symptoms, and presenting unique challenges to diagnosis and treatment.

All postconcussive subjective symptoms, including insomnia, seem to be shared by multiple concussion, PTSD symptoms, depressive symptoms, and combat experience. Yet multiple concussion by itself appears to contribute less to cognitive complaints and insomnia than it does to sensory, somatic, and vestibular complaints. This is a unique finding in the literature, possibly because previous studies have inadequately controlled for covariates that influence these subjective symptoms. If this finding is replicated in other samples, then these complaints may need to be more heavily weighted to better understand the unique contribution of concussions to persistent symptom reporting.

From the perspective of treating persistent postconcussive symptoms, however, distinguishing between the independent effects of concussion from emotional factors may not always be desired. Given that concussion is associated with increased odds of PTSD $(\mathrm{OR}=2.5)$, depression $(\mathrm{OR}=2.2)$, and anger $(\mathrm{OR}=2.4)$, independent of combat experience (Table 1), it is important to appreciate emotional factors as frequently comorbid with multiple concussion. Thus, clinicians' consideration of the effects of concussion on PPCS for determination of illness severity, and possibly even for treatment planning, need not be as analytically separated as is necessary for research.

Research to improve understanding of the unique contributions of various components of the wounds of war, as well as ways to better appreciate their interaction resulting in the gestalt experienced by the veteran, is necessary. Therefore, although it is important to determine the unique contributions of these various factors, it is also important to appreciate that separating them may lead to an underestimation of their combined effects.

Based on these results, it seems premature to recommend cessation of assessments for concussion post-deployment. Further, because there is so much comorbidity in this population, further research identifying the independent and combined causes of persistent symptoms should prove useful in both evaluating the functioning of the individual, as well as supporting the development of interventions that are tailored to the needs of those with specific symptom clusters. ${ }^{56}$ Future research that follows a cohort prospectively to better understand the time-course and causality of symptoms associated with concussion, as well as identifying if the context of the concussion (such as combat, assault, or accident), will also be of importance in the understanding and treatment of concussion and associated symptoms.

\section{Acknowledgments}

The opinions or assertions contained herein are the private views of the authors and are not to be construed as official or as reflecting the views of the US Department of Veterans Affairs, Department of the Navy, the Department of Defense, the United States Government, or the University of Hawaii.

This work was supported by the U.S. Navy Bureau of Medicine and Surgery, Wounded, Ill, and Injured Directorate, as well as with resources and the use of facilities at the US Department of Veterans Affairs, National Center for PTSD, Pacific Islands Health Care System.

We would like to thank the following persons for their assistance in data collection and comments on the article: James Drane, Jon Farris, and Lindsay Ohara Long of Anthrotronix, Inc., and Laurel King for her preparation of the manuscript. 


\section{Author Disclosure Statement}

No competing financial interests exist.

\section{References}

1. National Center for Injury Prevention and Control (2003). Report to Congress on Mild Traumatic Brain Injury in the United States: Steps to Prevent a Serious Public Health Problem. Centers for Disease Control and Prevention: Atlanta, GA.

2. Polusny, M.A., Kehle, S.M., Nelson, N.W., Erbes, C.R., Arbisi, P.A., and Thuras, P. (2011). Longitudinal effects of mild traumatic brain injury and posttraumatic stress disorder comorbidity on postdeployment outcomes in national guard soldiers deployed to Iraq. Arch. Gen. Psychiatry 68, 79-89.

3. Smith, T.C., Ryan, M.A.K., Wingard, D.L., Slymen, D.J., Sallis, J.F., Kritz-Silverstein, D., and Millennium Cohort Study, T. (2008). New onset and persistent symptoms of post-traumatic stress disorder self reported after deployment and combat exposures: prospective population based US military cohort study. BMJ 336, 366-371.

4. Tanelian, T., and Jaycox, L.H. (2008). Invisible Wounds of War: Psychological and Cognitive Injuries, their Consequences, and Services to Assist Recovery. RAND Corporation: Santa Monica, CA.

5. McCrea, M., Guskiewicz, K.M., Marshall, S.W., Barr, W., Randolph, C., Cantu, R.C., Onate, J.A., Yang, J., and Kelly, J.P. (2003). Acute effects and recovery time following concussion in collegiate football players: the NCAA Concussion Study. JAMA 290, 2556-2563.

6. Warden, D.L., Bleiberg, J., Cameron, K.L., Ecklund, J., Walter, J., Sparling, M.B., Reeves, D., Reynolds, K.Y., and Arciero, R. (2001). Persistent prolongation of simple reaction time in sports concussion. Neurology 57, 524-526.

7. Guskiewicz, K.M., Marshall, S.W., Bailes, J., McCrea, M., Cantu, R.C., Randolph, C., and Jordan, B.D. (2005). Association between recurrent concussion and late-life cognitive impairment in retired professional football players. Neurosurgery 57, 719-726.

8. Guskiewicz, K.M., McCrea, M., Marshall, S.W., Cantu, R.C., Randolph, C., Barr, W., Onate, J.A., and Kelly, J.P. (2003). Cumulative effects associated with recurrent concussion in collegiate football players: the NCAA Concussion Study. JAMA 290, 2549-2555.

9. Alves, W., Macciocchi, S.N., Barth, J.T., and J. (1993). Postconcussive symptoms after uncomplicated mild head injury. Trauma Rehabil. 8, 48-59. AUTHOR: Please fill in fourth author.

10. Deb, S., Lyons, I., and Koutzoukis, C. (1999). Neurobehavioural symptoms one year after a head injury. Br. J. Psychiatry 174, 360-365.

11. Dikmen, S., McLean, A., and Temkin, N. (1986). Neuropsychological and psychosocial consequences of minor head injury. J. Neurol. Neurosurg. Psychiatry 49, 1227-1232.

12. Hartlage, L.C., Durant-Wilson, D., and Patch, P.C. (2001). Persistent neurobehavioral problems following mild traumatic brain injury. Arch. Clin. Neuropsychol. 16, 561-570.

13. Luis, C.A., Vanderploeg, R.D., and Curtiss, G. (2003). Predictors of postconcussion symptom complex in community dwelling male veterans. J. Int. Neuropsychol. Soc. 9, 1001-1015.

14. Hoffer, M.E., Gottshall, K.R., Moore, R., Balough, B.J., and Wester, D. (2004). Characterizing and treating dizziness after mild head trauma. Otol. Neurotol. 25, 135-138.

15. Belanger, H.G., Spiegel, E., and Vanderploeg, R.D. (2010). Neuropsychological performance following a history of multiple self-reported concussions: a meta-analysis. J. Int. Neuropsychol. Soc. 16, 262-267.

16. Vanderploeg, R.D., Curtiss, G. and Belanger, H.G. (2005). Long-term neuropsychological outcomes following mild traumatic brain injury. J. Int. Neuropsychol. Soc. 11, 228-236.

17. Cooper, D.B., Kennedy, J.E., Cullen, M.A., Critchfield, E., Amador, R.R., and Bowles, A.O. (2011). Association between combat stress and post-concussive symptom reporting in $\mathrm{OEF} / \mathrm{OIF}$ service members with mild traumatic brain injuries. Brain Inj. 25, 1-7.

18. Hoge, C.W., McGurk, D., Thomas, J.L., Cox, A.L., Engel, C.C., and Castro, C.A. (2008). Mild traumatic brain injury in U.S. Soldiers returning from Iraq. N. Engl. J. Med. 358, 453-463.

19. Iverson, G.L. (2006). Misdiagnosis of the persistent postconcussion syndrome in patients with depression. Arch. Clin. Neuropsychol. 21, 303-310.

20. Lange, R.T., Iverson, G.L., and Rose, A. (2011). Depression strongly influences postconcussion symptom reporting following mild traumatic brain injury. J. Head Trauma Rehabil. 26, 127-137.
21. Ponsford, J., Cameron, P., Fitzgerald, M., Grant, M., Mikocka-Walus, A., and Schönberger, M. (2012). Predictors of postconcussive symptoms 3 months after mild traumatic brain injury. Neuropsychology 26, 304-313.

22. Hoge, C.W., Goldberg, H.M., and Castro, C.A. (2009). Care of war veterans with mild traumatic brain injury-flawed perspectives. N. Engl. J. Med. 360, 1588-1591.

23. Baugh, C.M., Stamm, J.M., Riley, D.O., Gavett, B.E., Shenton, M.E., Lin, A., Nowinski, C.J., Cantu, R.C., McKee, A.C., and Stern, R.A. (2012). Chronic traumatic encephalopathy: neurodegeneration following repetitive concussive and subconcussive brain trauma. Brain Imag. Behav. 6, 244-254.

24. Strain, J., Didehbani, N., Cullum, C.M., Mansinghani, S., Conover, H., Kraut, M.A., Hart, J., Jr., and Womack, K.B. (2013). Depressive symptoms and white matter dysfunction in retired NFL players with concussion history. Neurology 81, 25-32.

25. McKee, A.C., Cantu, R.C., Nowinski, C.J., Hedley-Whyte, E.T., Gavett, B.E., Budson, A.E., Santini, V.E., Lee, H.S., Kubilus, C.A., and Stern, R.A. (2009). Chronic traumatic encephalopathy in athletes: progressive tauopathy after repetitive head injury. J. Neuropathol. Exp. Neurol. 68, 709-735.

26. Bryan, C.J. (2013). Repetitive traumatic brain injury (or concussion) increases severity of sleep disturbance among deployed military personnel. Sleep 36, 941-946.

27. Bryan, C.J., and Clemens, T.A. (2013). Repetitive traumatic brain injury, psychological symptoms, and suicidal risk in a clinical sample of deployed military personnel. JAMA Psychiatry 70, 686-691.

28. Meares, S., Shores, E.A., Taylor, A.J., Batchelor, J., Bryant, R.A., Baguley, I.J., Chapman, J., Gurka, J., and Marosszeky, J.E. (2011). The prospective course of postconcussion syndrome: the role of mild traumatic brain injury. Neuropsychology 25, 454-465.

29. Kizilbash, A.H., Vanderploeg, R.D., and Curtiss, G. (2002). The effects of depression and anxiety on memory performance. Arch. Clin. Neuropsychol. 17, 57-67.

30. Schiehser, D.M., Delis, D.C., Filoteo, J.V., Delano-Wood, L., Han, S.D., Jak, A.J., Drake, A.I., and Bondi, M.W. (2011). Are self-reported symptoms of executive dysfunction associated with objective executive function performance following mild to moderate traumatic brain injury? J. Clin. Exp. Neuropsychol. 33, 704-714.

31. Guskiewicz, K.M., Marshall, S.W., Bailes, J., McCrea, M., Harding, H.P., Jr., Matthews, A., Mihalik, J.R., and Cantu, R.C. (2007). Recurrent concussion and risk of depression in retired professional football players. Med. Sci. Sports Exerc. 39, 903-909.

32. Vasterling, J.J., Proctor, S.P., Amoroso, P., Kane, R., Heeren, T., and White, R.F. (2006). Neuropsychological outcomes of army personnel following deployment to the Iraq war. JAMA 296, 519-529.

33. Reger, M.L., Poulos, A.M., Buen, F., Giza, C.C., Hovda, D.A., and Fanselow, M.S. (2012). Concussive brain injury enhances fear learning and excitatory processes in the amygdala. Biol. Psychiatry 71, 335-343.

34. Morrisette, S.B., Woodward, M., Kimbrel, N.A., Meyer, E.C., Kruse, M.L., Dolan, S., and Guliver, S.B. (2011). Deployment-related TBI, persistent postconcussive symptoms, PTSD, and depression in OEF/ OIF veterans. Rehabil. Psychol. 56, 340-350.

35. Maguen, S., Madden, E., Lau, K.M., and Seal, K. (2012). The impact of head injury mechanism on mental health symptoms in veterans: do number and type of exposures matter? J. Trauma. Stress 25, 3-9.

36. Kennedy, J.E., Clement, P.F., and Curtiss, G. (2003). WAIS-III processing speed index scores after TBI: the influence of working memory, psychomotor speed and perceptual processing. Clin. Neuropsychol. 17, 303-307.

37. Sosnoff, J.J., Broglio, S.P., Hillman, C.H., and Ferrara, M.S. (2007). Concussion does not impact intraindividual response time variability. Neuropsychology 21, 796-802.

38. Kay, T., Newman, B., Cavalio, M., Ezrachi, O., and Resnick, M (1992). Toward a neuropsychological model of functional disability after mild traumatic brain injury. Neuropsychology 6, 371384.

39. Wesensten, N., and Balkin, T. (2010). Cognitive sequelae of sustained operations, in: Military Neuropsychology. C. Kennedy, J. Moore (eds). Springer: New York, pps. 297-320.

40. Vasterling, J., MacDonald, H., Ulloa, E., and Rodier, N. (2010). Neuropsychological correlates of PTSD: A military perspective, in: Military Neuropsychology. C. Kennedy, J. Moore, J. (eds). Springer: New York, pps. 321-360. 
41. Lathan, C., Spira, J.L., Bleiberg, J., Vice, J., and Tsao, J.W. (2013). Defense Automated Neurobehavioral Assessment (DANA)-psychometric properties of a new field-deployable neurocognitive assessment tool. Mil. Med. 178, 365-371.

42. Spira, J. (2013). The role of multiple concussions on emotional and cognitive functioning in combat veterans. Proceedings of Military Health System Research Symposium, Ft. Lauderdale, FL.

43. Bliese, P.D., Wright, K.M., Adler, A.B., Cabrera, O., Castro, C.A., and Hoge, C.W. (2008). Validating the primary care posttraumatic stress disorder screen and the posttraumatic stress disorder checklist with soldiers returning from combat. J. Consult. Clin. Psychol. 76, 272-281.

44. Prins, A., Ouimette, P., Kimerling, R., Camerond, R.P., Hugelshofer, D.S., Shaw-Hegwer, J., Thrailkill, A., Gusman, F.D., and Sheikh, J.I. (2004). The primary care PTSD screen (PC-PTSD): development and operating characteristics. Int. J. Psychiatry Clin. Pract 9, 9-14.

45. Prins, A., Ouimette, P., Kimerling, R., Camerond, R.P., Hugelshofer, D.S., Shaw-Hegwer, J., Thrailkill, A., Gusman, F.D., and Sheikh, J.I. (2004). The primary care PTSD screen (PC-PTSD): development and operating characteristics: Corrigendum. Int. J. Psychiatry Clin. Pract. 9, 151-152.

46. Kroenke, K., Strine, T.W., Spitzer, R.L., Williams, J.B., Berry, J.T., and Mokdad, A.H. (2009). The PHQ-8 as a measure of current depression in the general population. J. Affect. Disord. 114, 163-173.

47. Keane, T.M., Fairbank, J.A., Caddell, J.M., Zimering, R.T., Taylor K.L., and Mora, C.A. (1989). Clinical evaluation of a measure to assess combat exposure. Psychol. Assess. 1, 53-55.

48. Meterko, M., Baker, E., Stolzmann, K.L., Hendricks, A.M., Cicerone, K.D., and Lew, H.L. (2012). Psychometric assessment of the Neurobehavioral Symptom Inventory-22: the structure of persistent postconcussive symptoms following deployment-related mild traumatic brain injury among veterans. J. Head Trauma Rehabil. 27, 55-62.

49. Bastien, C.H., Vallières, A., and Morin, C.M. (2001). Validation of the Insomnia Severity Index as an outcome measure for insomnia research. Sleep Med. 2, 297-307.

50. Buysse, D.J., Reynolds, C.F., 3rd, Monk, T.H., Berman, S.R., and Kupfer, D.J. (1989). The Pittsburgh Sleep Quality Index: a new in- strument for psychiatric practice and research. Psychiatry Res 28, 193-213.

51. Cohen, J. (1988). Statistical Power Analysis for the Behavior Sciences. Erlbaum: Hillsdale, NJ.

52. Marin, J.R., Weaver, M.D., Yealy, D.M. and Mannix, R.C. (2014). Trends in visits for traumatic brain injury to emergency departments in the United States. JAMA 311, 1917-1919.

53. Hoge, C.W., Castro, C.A., Messer, S.C., McGurk, D., Cotting, D.I. and Koffman, R.L. (2004). Combat duty in Iraq and Afghanistan, mental health problems, and barriers to care. N. Engl. J. Med. 351, 13-22.

54. MacDonald, C.L., Johnson, A.M., Wierzechowski, L., Kassner, E. Stewart, T., Nelson, E.C., Werner, N.J., Zonies, D., Oh, J., Fang, R. and Brody, D.L. (2014). Prospectively assessed clinical outcomes in concussive blast vs nonblast traumatic brain injury among evacuated US military personnel. JAMA Neurol. 71, 994-1002.

55. Ivins, B.J., Kane, R. and Schwab, K.A. (2009). Performance on the Automated Neuropsychological Assessment Metrics in a nonclinical sample of soldiers screened for mild TBI after returning from Iraq and Afghanistan: a descriptive analysis. J. Head Trauma Rehabil. 24, 24-31.

56. Walter, K.H., Kiefer, S.L. and Chard, K.M. (2012). Relationship between posttraumatic stress disorder and postconcussive symptom improvement after completion of a posttraumatic stress disorder/ traumatic brain injury residential treatment program. Rehabil. Psychol. $57,13-17$.

Address correspondence to:

James L. Spira, PhD, MPH, ABPP

National Center for PTSD

US Department of Veterans Affairs

3375 Koapaka Street, I-560

Honolulu, HI 96819

E-mail: James.Spira@va.gov 